This is a postprint version of the following published document:

Van Hooland, S., Vandooren, F. \& Méndez Rodríguez,

E. M. (2011). Opportunities and risks for libraries in applying for European funding. The Electronic Library, 29 (1), pp. 90-104.

DOI: $10.1108 / 02640471111111451$

(C) Emerald Group Publishing Limited, 2011 


\title{
Opportunities and risks for libraries in applying for European funding
}

\author{
Seth van Hooland \\ Library and Information Science Department, \\ Universidad Carlos III de Madrid, Madrid, Spain \\ Françoise Vandooren \\ Libraries Head Office, UniversitéLibre de Bruxelles, Brussels, Belgium \\ Eva M. Méndez Rodríguez \\ Library and Information Science Department, \\ Universidad Carlos III de Madrid, Madrid, Spain
}

\begin{abstract}
Purpose - This paper seeks to analyse the opportunities and potential risks for libraries applying for European support to fund projects regarding digitisation or availability of their already digitised content. The European Commission has a range of specific funding programs devoted to access, use and preservation of digital cultural heritage, so libraries and other "cultural institutions" holding European heritage are the natural applicants for this kind of calls. Sometimes, however, they do not know how to apply and fully understand the advantages and commitments involved. This paper aims to help libraries to understand European funding programs.

Design/methodology/approach - The paper has complementary experience with respect to applications and participation in EU-funded projects, as well as the evaluation of proposals and the reviewing of approved projects. Apart from the lessons drawn from the personal experiences of the paper, the content is based on the most recent documentation and information about the Call For Proposals (CFP) made available by the European Commission.

Findings - Competition among proposals for European funding in the context of Digital Libraries (DLs) has grown considerably over the last few years. Therefore, it is essential for potential applicants to ensure the quality of their proposal by matching its content to the objectives of the Call and meeting the relevant evaluation criteria. In addition, the scope of the proposal needs to be embedded within the long-term research and management strategy of the institutions applying to ensure both a successful application procedure and maximum sustainability of the project.

Originality/value - Apart from the documentation offered by the European Commission and several public reports of consultancy firms, no previous papers have been published which provide an insight into the workflow of the submission and evaluation of proposals for European funding in the domain of Digital Libraries.
\end{abstract}

\section{Keywords}

Library management, Government policy, Information technology, Project finance, Europe 


\section{Introduction}

In the past decade, the European Commission's information policy has included the development of the old dream (started in the mid-1990s with Bibliotheca Universalis (www.bl.uk/gabriel/bibliothecauniversalis) to create a European digital library, which includes and makes available the main European cultural and scientific content (Raitt, 2000). With this aim, the EC has invested considerably in the digitisation of cultural heritage, and more specifically in making European content more accessible, usable and exploitable, developing different Digital Libraries throughout the Member States.

The focal points of the past and current funding programmes, which aim at supporting research into and development of digital libraries, are excellent examples of the strategic issues to be tackled by libraries in the next decade, such as long-term digital preservation, overcoming restrictive intellectual property rights (IPR) issues, the aggregation of multilingual content and metadata, and addressing end-user needs in a more effective manner.

The application procedure for European funding is generally considered to be very complex and cumbersome, which discourages institutions from applying. Also, sometimes particular libraries and other cultural institutions are not aware of the European programmes, or they are but do not think they would get funding to make their content more visible and available on the web. This paper provides a clear overview of the possibilities and interest, but also the pitfalls, when applying for European funding in the framework of the Digital Libraries (DL) Initiative (http://ec. europa.eu/information_society/activities/digital_libraries/index_en.htm). Practical examples and recommendations will provide a clearer view of the feasibility and the appropriateness of putting effort into the application procedure.

The paper starts with some necessary reflections on the problematic tension between the projectbased funding of DL's projects and the sustainability of their outcomes, and gives an international overview of the available bibliography regarding this topic. It then focuses on the funding policy of the European Commission by giving a basic explanation of the overall context of European funding, followed by a description of the opportunities and risks of applying for, and participating in, European projects. The majority of the paper concentrates on the application procedure, beginning with the identification of a call of interest and moving on to the development of a specific project, the search for project partners and finally the drafting of the proposal. An overview of the evaluation procedure of proposals and the available support for applicants, followed by a summary of the essential recommendations in the conclusions, completes the paper.

The tension between project-based funding and sustainable outcomes Even though providing electronic access to resources and their metadata are currently considered a core responsibility of cultural heritage institutions, the funding to enable this access often comes from non-structural and external sources (Griffin, 2005; Liew, 2009). From a historical point of view, the current digitisation of analogue collections, but also the creation of their metadata and the development of the back and frontend of the collections management system, was considered, at the end of the 1990s, and the beginning of the last decade:

- an additional service provided to the users; and

- projects with a clear start and end point. 
Therefore, it seemed only logical to look for additional financial support outside the structural funds of the institution. This vision, which accompanied the first decade of digitisation projects, has now been superseded by reality as we have come to realise that:

- electronic access to resources stands high on the list of user needs and is now considered a core responsibility of cultural heritage institutions; and

- digitisation projects involve important permanent maintenance costs.

Several authors (Smith, 2003; Hamilton, 2004) have pointed out that digitisation outcomes may not be sustainable when solely reliant on government grants. One of the answers to this problem has been the development of business models aimed at establishing Return of Investment (ROI) policies or, at least achieving self-sufficiency for maintenance (Geser and Mulrenin, 2002).

However, experience has come to show that self-sustainability of digitisation projects cannot be attained in most cases. A 2008 report published by Online Computer Library Center (OCLC) Programmes and Research offers insights into and results of the Research Libraries Group's Cultural Materials and Trove.net project, which were initiated in 1999 and launched in 2002 with the specific goal of studying the possibilities for collaborative large-scale digitisation projects to sustain themselves (Erway, 2008). The outcomes of the project were negative due to the lack of interesting content for the corporate world. Big cultural heritage institutions may possess a small number of very attractive and iconic images that can be licensed at competitive rates, but the bulk of historical images are not of sufficient interest to build a viable business plan based on image licensing.

Furthermore, cultural heritage institutions around the world are commonly encouraged to pro-actively search for external funding possibilities, particularly in harsh economic times. In Europe, given that programmes of the European Commission offer the most important grants available in this region, middle-sized to large libraries with an international network should consider participating, or at least become aware of the funding criteria and application procedures.

\section{Crash course on European funding}

Before getting into the details of the application and evaluation procedure, a more general outline of the European funding context needs to be spelled out. Specific funding programmes usually serve to support longer-term strategic or political goals. The Framework Programmes (FPs) for research and technological development (R\&D) are consecutive multi-annual programmes around which European research and development activities are structured and funded. FPs are the European Union's chief instruments for funding research over a particular period of time; the current FP, Seventh Framework Programme (FP7) (http://cordis.europa.eu/fp7/home_en.html) covers projects from 2007 to 2013, bringing together all research-related $\mathrm{EU}$ initiatives under a common framework, playing a crucial role in reaching the goals of growth, competitiveness and employment. As was the case for the previous Framework Programme (FP6), FP7's main objective is to help the construction of the European Research Area (ERA). In this endeavour, Information and Communication Technologies (ICT) have an important role to play to achieve the ERA, particularly as applied to cultural and scientific digital content, which is the focus of this paper. Framework Programmes are implemented through annual work programmes, which 
set the objectives and funding schemes for specific application domains and the calendar for Calls For Proposals (CFP). Challenges, consisting of specific objectives or actions, set out the concrete goals to be attained. Calls are published to announce the planning and the constraints of the application procedure to obtain funding within the context of the objectives or actions.

For example, within the current FP7, the ICT Digicult (Digital Culture) Work Programmes defines the research priorities for 2009-2010 within the cultural heritage domain, and addressed under Challenge 4, Objective 4.1 a limited set of problems to be tackled within the context of "Digital Libraries and Preservation". Within the same call, different so-called financial instruments or funding schemes can apply, which stipulate the type and the amount of the funding, as a call can have different targets which require different implementation measures. For instance, the ICT Call 6, which announces the funding criteria for Challenge 4, Objective 4.1 has four different funding schemes. When preparing a proposal, it is essential to understand the differences between them, as the type and the amount of funding radically differ from one funding scheme to the other. For example, within the funding scheme "thematic networks" of the past eContentPlus programme, only the project coordinator can claim personnel costs, the other project participants can only get funding for travel expenses.

Apart from the financial structures, which steer the funding processes, potential applicants must also understand the rationale behind the establishment of a consortium of project partners. The participants in a project may take the following three roles: coordinator, beneficiaries or subcontractors. First of all, each proposal must include a coordinator, which represents the consortium and bears overall responsibility. The remaining partners in the consortium are called beneficiaries. They may opt to outsource a part of their work to subcontractors through a call for tender procedure, but the project partners remain responsible for the quality of the completed work.

A consortium should consist as much as possible of partners with complementary competencies and they must represent different EU Member States. Depending on the funding scheme, a combination of public and private organisations, and/or of content providers and technology/service providers might be required or recommended. In the case of a Digital Library project for example, content providers can make their digitised books and the associated metadata available, whereas the technology providers can implement a service, which allows aggregating the content of different providers and making it searchable. According to specific competencies, each partner is assigned to one or more Work Packages (WPs). These are major sub-divisions of the proposed project with a well-defined start and end point, consisting normally of a deliverable or a milestone in the overall project. Deliverables are often written reports, but can also consist of working prototypes or other kind of services or products.

\section{Opportunities and risks}

What exactly motivates institutions to apply for European funding? Obtaining external budgets to support the growing costs involved with the digitisation of library collections and related services is clearly the major motivation. Project-based funding for digitisation activities is also available at national, regional and local level, but the budgets and the time span of the projects are considerably smaller. Depending on the type of funding scheme used within Objective ICT-2009. 4.1 (to which we have already 
referred to previously) the funding ranges from a minimum of $€ 28$ million to a maximum of $€ 39$ million for the Integrated Projects, (i.e. large-scale integrated projects) and €17-28 million for Specific Targeted Research Projects (i.e. small or medium-scale focused research actions). The funding percentage varies from one scheme to the other, but in general each applicant must demonstrate that he is in a position to assume his own cost share of 50 per cent of the estimated overall budget for the project. Within a typical budget, the large majority is attributed to staff costs. As a rule of thumb, no more than 7-10 per cent can be attributed to project management, but this will depend on the type of project.

Apart from the direct financial gains an institution can hope to obtain, participation in EU-funded projects allows organisations to recognise value from and extend their competencies. National libraries such as the Koninklijke Bibliotheek in The Netherlands or the British Library have been able to come to terms with disruptive technologies such as digitisation within the context of the European projects they have participated in. By doing so, they have managed to re-establish their national leadership regarding the implementation of new technologies and the development of a long-term ICT strategy. Smaller organisations, such as university libraries, should also take the opportunity to share their expertise in some domain and gain technical experience from expert partners in other fields. Over the last decade, European funding has allowed libraries to develop new digital services, for example an institutional repository, or to increase the visibility of specific digital collections, through an e-thesis portal for example, and apply new standards like the OAI (Open Archives Initiative) protocol for metadata harvesting.

There are, however, also clear risks involved when applying for funding. Obviously, the most evident risk for an applicant is the non-acceptance of the proposal. Success rates of proposals vary across the different programmes, but the competition has grown considerably over the last five years. Successful applicants of past programmes tend to re-apply for funding at the end of their current project, while new organisations continuously join the group of applicants. Depending on the number of high-level proposals with the same objective and content, the level of competition can be very high. Although this can only be done in an informal manner by depending on one's professional network, applicants should try to detect whether other organisations are drafting a similar proposal. If it is the case, it is recommendable to join forces instead of entering into competition. The putative consortium needs to be willing to take the risk of investing one to several persons and months in drafting the proposal, which might not get funded. It is very difficult to give an overall success rate of applications, as this percentage varies enormously from one call to the other, due to the differing number of applications. The percentage of acceptance for the popular eContent (http://cordis.europa.eu/econtent/) and eContentplus (http://ec.europa.eu/information_society/activities/econtentplus/programme/ index_en.htm) programmes for example varied from around 10-12 per cent, but around 50 per cent of the applicants of the 2009 call of the Competitiveness and Innovation framework Programme (CIP) ICT Policy Support Programme (ICT PSP) (http://ec.europa.eu/information_society/activities/ict_psp/about/ index_en.htm) were accepted, as there were only a few applicants.

Once the proposal does get approved, there are still a number of issues, which can arise. The reimbursement of expenses is scheduled over the whole period of the project, 
and depends on the submission of deliverables. The success of a project is the result of a common effort by all the project partners, so if one of the partners does not respect deadlines or does not deliver quality results, the whole consortium runs the risk of receiving the funding at a later stage or not at all. It is therefore important to know future partners or to collect information about their reliability from coordinators of previous projects in which they have participated.

Particular caution should also be given to the human resources management, which can become a source of major problems if not well prepared. For example it is not straightforwardly easy to hire a skilled programmer on a part-time basis or only for a limited period of time. On the other hand, if you plan to use internal resources, you should think about how to adapt the current tasks of these workers. Regular staff, are not always in the habit of working in a project-based manner, with tight deadlines, and the obligation of producing clear evidence of the impact of work, which is required by the European Commission.

\section{Scenario of project funding}

In this section, we will describe an overview of the steps to be taken when preparing a proposal. Figure 1 gives an overview of the different steps of the proposal submission process.

\section{Being aware of funding programmes and the launch of their Calls}

Finding one's way in the myriad of online information made available by the EC is no sinecure for novices. The main and best source of information is the CORDIS web site, which offers the latest news on FP7 funding. Subscription to the newsletter of the DG Information Society can also be a helpful way of keeping up to date with the latest news regarding funding programmes related to the library world. Following the launch of a Call, the European Commission organises "Information Days", where the call is explained in detail and attendees have the opportunity to interact with the programme officers as well as other potential applicants attending the InfoDay.

Table I presents a synthesis of current programmes of interest towards libraries. The ICT DigiCult programme is clearly oriented towards research, innovation and demonstration in the field of digital culture and Digital Libraries, with the intent to expand access, use and preservation of digital content. Second, the ICT PSP programme covers follow-on activities of the eContent and eContentplus programmes and focuses on providing more content and services towards users. The latest calls of these two programmes are presented in more details hereunder. Finally, the Infrastructures programme supports a combination of research, networking and service provision activities with the main goal of optimizing the infrastructures for the scientific communities, such as interoperable repositories.

For every work programme, a certain number of calls for proposals are planned, each dealing with some specific topics, and with a determined amount allocated to each topic.

The Objective 4.1 of the ICT DigiCult work programme concentrates on Digital Libraries and preservation. This objective could be of particular interest to libraries, as it sets out to tackle issues, which all organisations are currently facing, such as the problem of digital preservation. In particular, the following target outcomes for this objective have been identified: 
Figure 1.

Overview of the proposal submission process

$\begin{aligned} & \text { - identify a call for proposals of interest to you in CORDIS } \\ & \text { - identify your strengths/competencies or the content you can provide in relation to } \\ & \text { the programme } \\ & \text { for proposals }\end{aligned}$
$\begin{aligned} & \text { - identify the appropriate funding scheme } \\ & \text { - check the associated conditions regarding partners and funding } \\ & \text { funose } \\ & \text { scheme }\end{aligned}$
$\begin{aligned} & \text { - use the Ideal-ist partner search service: } \\ & \text { - to make a proposal and look for partners } \\ & \text { - or to join a proposal }\end{aligned}$
$\begin{aligned} & \text { - check financial or legal elements at the help desk } \\ & \text { - submit your idea to the pre-proposal check service for compliance/relevance with } \\ & \text { the programme }\end{aligned}$

- Part A administrative: summary; partner details; cost \& funding details

- Part B technical/work plan: work packages, list of deliverables, milestones, staff effort per partner

- clear relevance to the programme objectives

- strong impact

- solid implementation or project planning

- use the electronic proposal submission system to fill in the forms A and B
progressively
$\begin{gathered}\text { submit your } \\ \text { proposal }\end{gathered}$

- scalable systems and services for preserving digital content;

- advanced preservation scenarios;

- innovative solutions for assembling multimedia Digital Libraries for collaborative use in specific contexts and communities, enhancing scholarly understanding and experiences of digital cultural heritage;

- adaptive cultural experiences exploring the potential of ICT for creating personalised views of various forms of cultural expression;

- interdisciplinary research networks bridging technological domains, information and archival sciences, and social and cognitive sciences; and

- promoting the uptake of EC-funded research, enabling the deployment of new ICT-based cultural and memory preservation services, and leveraging the impact of associated national initiatives. 
Table I.

Synthesis of EU funding programmes related to digital libraries

\begin{tabular}{|c|c|c|c|}
\hline & ICT DigiCult & $\begin{array}{l}\text { ICT Policy Support } \\
\text { Programme }\end{array}$ & Infrastructures \\
\hline Activities & $\begin{array}{l}\text { Research on ICT and } \\
\text { demonstration }\end{array}$ & $\begin{array}{l}\text { Provision of content and } \\
\text { services }\end{array}$ & $\begin{array}{l}\text { RTD + networking + } \\
\text { services }\end{array}$ \\
\hline Call & Call 6 & Call 4 & Call 5 \\
\hline $\begin{array}{l}\text { Objective } \\
\text { or Theme }\end{array}$ & $\begin{array}{l}\text { ICT-2009.4.1. Digital } \\
\text { libraries and preservation }\end{array}$ & Theme 2: Digital libraries & ICT based e-Infrastructures \\
\hline Focus & $\begin{array}{l}\text { Digital culture and digital } \\
\text { libraries for expanding } \\
\text { access, use and preservation }\end{array}$ & $\begin{array}{l}\text { European Digital Library; } \\
\text { Open Access to scientific } \\
\text { content }\end{array}$ & $\begin{array}{l}\text { Scientific Information } \\
\text { Repository supporting the } \\
\text { European FP7 Research } \\
\text { Programme }\end{array}$ \\
\hline $\begin{array}{l}\text { Funding } \\
\text { schemes }\end{array}$ & $\begin{array}{l}\text { Collaborative projects, } \\
\text { network of excellence, } \\
\text { coordination and support } \\
\text { action }\end{array}$ & $\begin{array}{l}\text { Pilot type B, Thematic } \\
\text { Network, Best Practice } \\
\text { Network }\end{array}$ & $\begin{array}{l}\text { Combination of } \\
\text { collaborative projects and } \\
\text { coordination and support } \\
\text { actions }\end{array}$ \\
\hline $\begin{array}{l}\text { Call closed } \\
\text { on }\end{array}$ & 13 April 2010 & 1 June 2009 & 17 March 2009 \\
\hline $\begin{array}{l}\text { Foreseen } \\
\text { budget }\end{array}$ & $€ 69$ million & $€ 30$ million & lion \\
\hline
\end{tabular}

A more detailed description of this work programme can be found on the DigiCult related pages of the CORDIS web site. The call for this work programme has been closed on 13 April 2010. The budget foreseen for the objective "Digital Libraries and Digital Preservation" is $€ 69$ million.

The fourth call for the ICT PSP Programme includes a theme on digital libraries with the aim to improve accessibility, use and preservation of Europe's cultural heritage online. It also calls for experiments with open access to scientific information, exploring new paradigms for access and use. The following six objectives have been put forward:

(1) Coordinating Europeana.

(2) Enhancing/aggregating content in Europeana.

(3) Digitising content for Europeana.

(4) Access to European Rights Information/Registry of Orphan Works.

(5) Open access to scientific information.

(6) Statistics on cultural heritage digitisation activities.

Three types of funding schemes are available:

(1) Pilot type B: stimulating innovative use of ICT in public and private sector.

(2) Thematic network: mobilisation/exchange between practitioners and policy makers.

(3) Best Practice network: combining consensus building/ awareness raising/large scale implementation.

A detailed description of this work programme can be found on the ICT PSP pages of the CORDIS web site. The call has been closed on 1 June 2010. The budget foreseen is €30 million. 
Develop a project! Or join one...

After the identification of a Call of interest, there are two possible steps to be taken. Either you or your institution has an idea for a proposal or alternatively you may wish to join a group of partners who already have outlined the scope of a proposal. In both cases, it is of the utmost importance that the project is in line with the long-term strategy of your institution. The future sustainability of project outcomes is an important evaluation criterion for the European Commission. The better you can demonstrate that the proposed actions are in line with the experience and the future ambitions and agenda of your library or cultural institution, the more credit the proposal will receive. On the other hand, if the proposal is not accepted for funding, you might be able to re-use a slimmed down version of the proposed work plan for your own internal management processes, in which case the invested time in the proposal is not entirely lost.

Apart from the conformity of the proposal with your institution's strategy, your intentions need to be in line with the evaluation criteria. The proposals are evaluated along three criteria: relevance, impact and implementation. You must therefore carefully analyse the available funding programmes and detect which one allows you to match the work you set out in your proposal with one or more of the topics and associated funding schemes defined in the Call for Proposals. You must also evaluate whether your proposal, although very interesting, is really in the scope of the programme and the particular targeted objectives. For instance, the DigiCult Programme focuses on research on ICT, innovation and demonstration. Before applying for Objective ICT-2009.4.1, it might be useful to look at past and current ICT projects to get an idea of the R\&D activities that are being funded, and to examine past and current projects on digital preservation in order to build on their research results. For example, CASPAR and PLANETS are two large-scale projects that aim to test OAIS-based systems and tools (Open Archival Information System); and the project Digital Preservation Europe works towards coordination of national activities in preservation.

\section{Finding project partners}

The composition of the consortium of applicants is the following crucial step. Ideally, these are people you have already worked with in the past, but you may need some specific expertise, content or technology, which is not available in your immediate professional network. The CORDIS web site offers a partners search service which enables you to look for partners who already drafted a first version of a proposal but who lack partners, or institutions who do not yet have a concrete idea for a proposal but who provide a description of the type of content or service they offer, such as a private company which has specific experience in the field of Optical Character Recognition (OCR). For example, a search using the keyword «library» gives a list of entities and a short description of their proposal, the potential funding programme, what kind of partners they are looking for and who they are. Another helpful tool is the Ideal IST partner search service, which has been developed specifically for the ICT funding programmes.

When looking for partners you should keep in mind a geographical balance and involve both new and old EU Member States. Depending on the type of funding scheme, the participation of associated countries for example, Switzerland, Israel or 
Norway, may or may not be possible. Some funding programmes also strongly encourage the participation of Small and Medium-sized Enterprises (SMEs), in which case, the coordinator of the proposal must consider including more than one of those SMEs.

\section{Drafting the proposal}

The EC provides clear guidelines and templates for the actual writing process of the proposal. The format of the templates is directly linked to the evaluation criteria, which means that applicants should exactly and exclusively address the issues required in the fields of the templates. If not, applicants will be penalised by the independent experts during the evaluation process for not giving accurate information. Theoretically, the proposal can be written in any official language of the EU, but English is strongly recommended as it is the working language during the evaluation process of the proposals and will also very likely be the working language among the members of the consortium. For first time applicants, it can be helpful to take advantage of any pre-proposal checking service offered by the EC to check relevance with the funding programme.

Each proposal contains two distinctive parts: an administrative part about the proposal and the participants, and a scientific/technical part describing the objectives, work plan, implementation measures and expected impact. In the administrative part, each partner needs to outline its financial situation of the last fiscal year in detail, which might require some time. If the project gets accepted, this information needs to be certified by an auditor. The other key element of the administrative part is the envisioned budget. While developing your budget, you should be aware that only eligible costs can be taken into account, which are direct cost of personnel and subcontracting, travel and subsistence, and durable equipment. Indirect costs (also called "overheads") are calculated and declared, or you may opt for a flat rate of 20 per cent of the direct costs. The amount requested to the Commission is a percentage of the budget; the rates vary with the work programmes and the funding schemes. It may range from 50-80 per cent of eligible costs. Note that if the project is selected, the estimated budget and the EC contribution are subject to discussions when the Grant Agreement is negotiated with the European Commission.

The second part of the proposal requires a detailed description of how the project will be carried out (what might be called "Statement of Work" (SoW) or Description of Work (DoW) in a commercial contract). It describes every work package with its objectives, responsible person/institution, deliverables, milestones, staff effort per partner and per work package, etc. Table II illustrates the management of different work packages, which typically occur in a project. Required or often recurring work packages are project management, user requirements, awareness and dissemination, and assessment and evaluation.

\section{Evaluation process}

After an eligibility check by the Commission, a number of independent experts are recruited to evaluate the proposals. The experts first perform an individual assessment of the proposals and award proposal scores with concise but explicit justifications. Once all the experts to who a proposal has been assigned have completed their individual assessment, a consensus meeting takes place during which the individual 
Table II.

Example of the division of a project in work packages

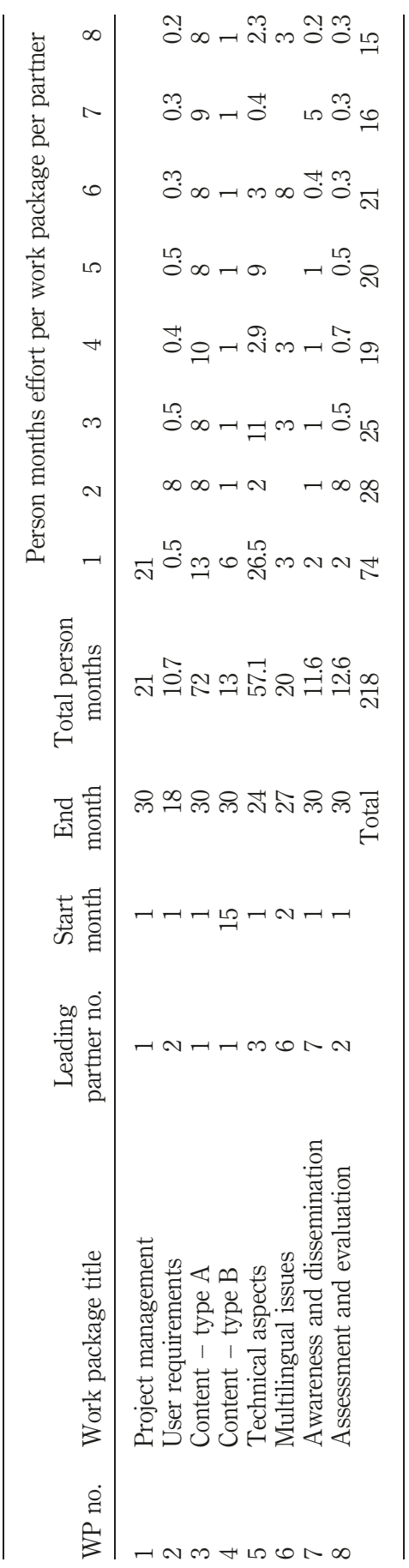


scores are commented on and discussed. Under the supervision of a representative of the Commission, a consensus report is drawn up in which scores for each evaluation criterion are given, accompanied by comments which will be communicated to the proposal coordinator. If no consensus can be reached among the experts, the Commission may ask additional experts to examine the proposal. The third and final step is then taken during the panel meeting, which allows the experts to formulate their recommendations to the Commission, after the latter has an overview of the results of the consensus step. The panel meeting, chaired by the Commission, allows the experts to ensure the consistency of the different consensus reports for a given area, and where necessary, propose a new set of consensus scores. The results of the panel meeting are recorded in an Evaluation Summary Report for each proposal, which is then sent to each proposal coordinator. It conveys the results of the technical evaluation of the proposal, consisting of the score and the comments made by the experts. Figure 2 gives an overview of the overall selection procedure.

\section{Available support}

Extensive support is available for applicants. Each Member State has a National Contact Point (http://cordis.europa.eu/fp7/ncp_en.html) who can help with general

\section{Figure 2.}

Evaluation and selection

$\mathrm{p}$

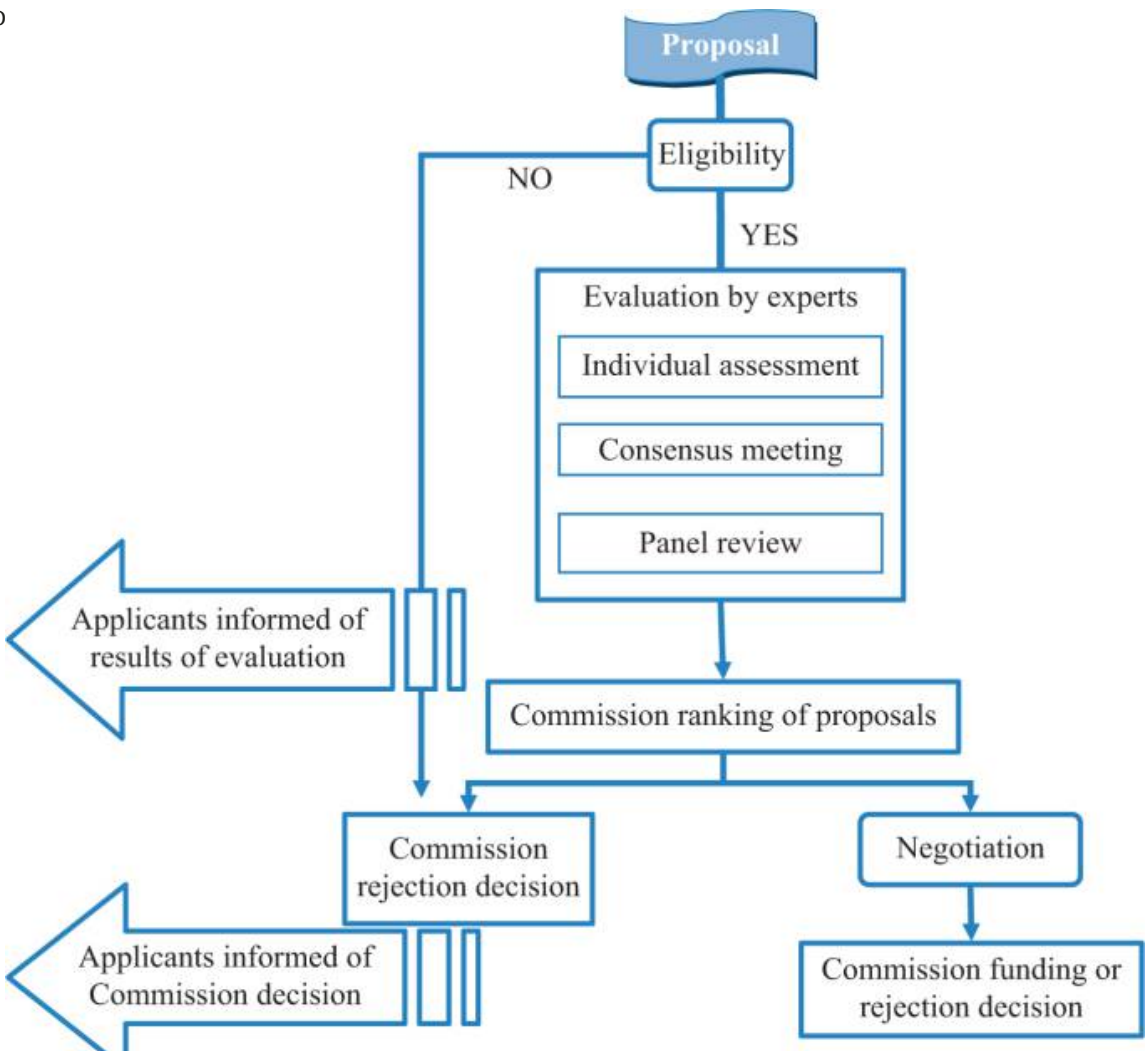


issues in your own language. The European Commission itself also offers assistance at different levels. Each call is accompanied by a Guide for Applicants. Once they start writing the proposal, applicants can make use of a pre-proposal check service, to ensure that the overall idea and stakeholders of a proposal are in line with the specific objectives of the call and funding programme.

Outsourcing the proposal writing may also be an option to consider. Drafting a well-written proposal, which is in line with the requirements and the evaluation criteria of the Commission has practically become a profession in its own right. A growing number of companies and individual consultants are offering their services, writing proposals tailored specifically to your needs. These services can range from reviewing and correcting a proposal drafted by the applicants, the organisation of a workshop during which the consultant works together with the participants to come to a proposal, or the complete drafting of the proposal by the consultant, based on interviews with the different participants.

Consultant services are expensive, but they can save you time and if you do not have extensive experience with the drafting and submission of proposals, the end result will probably be better with the help of an experienced consultant who understands the required format of proposals and the submission process. However, as it is the obvious goal of consultants to write up a "wining" proposal, unscrupulous professionals might make unrealistic promises in the proposal, which bring the institution into conflict with the European Commission on an effective funding of their proposal.

\section{Conclusions}

This paper has delivered a concise introduction to the world of European funding from the specific perspective of libraries and other eligible cultural institutions and has pointed out both the opportunities and the risks. Applying for external funding is a logical choice for libraries when confronted with the rising costs of digitisation and related services and the European Commission offers the opportunity of funding part of your libraries' digital projects, offering at the same time the opportunity of being part of the European Digital Cultural Heritage (http://cordis.europa.eu/fp7/ict/ telearn-digicult/digicult-objectives_en.html), made available through Europeana (www.europeana.eu). Currently, libraries can apply until mid April 2010 for funding under the Objective 4.1 of the ICT DigiCult work programme, which concentrates on Digital Libraries and preservation projects, or they can apply until June 2010 for funding under a new ICT PSP call.

However, competition for funding has grown considerably over the last years and potential applicants should therefore be aware that only a minority of the proposals get funding at the end of the evaluation process. Applying for European funding cannot be seen as an ad hoc decision, but needs to be carefully planned. When drafting the proposal, the effort should be divided over all of the evaluation criteria, as not meeting any one of the criteria may lead to failing one or multiple thresholds that need to be met to receive funding. As a general rule, the proposal should state as explicitly as possible why the proposal meets the evaluation criteria.

Finally, the procedure to apply for funding from the European Commission, often regarded as a cumbersome and administrative endeavour, has important lessons to offer to cultural heritage institutions. Confronted with rising accountability issues, it 
can be a very useful exercise for libraries to draft a viable business plan, even if intervention with public funds constitutes the basis for the project. Hamilton rightly closes up his article on sustainability for Digital Libraries by mentioning that the formal business plan required by many funders should not be regarded as one more bureaucratic hurdle but the passport to a successful, sustainable Digital Library (Hamilton, 2004). Furthermore, the work on the application procedure for European funding can help to adopt a more user-centered vision for digital projects, instead of a solely collection-centered approach.

\section{References}

Erway, R. (2008), Seeking Sustainability: Technical Report, OCLC Programmes and Research,

OCLC, Columbus, OH, available at: www.oclc.org/research/publications/library/2008/ 2008-03.pdf (accessed 22 December 2009).

Geser, G. and Mulrenin, A. (2002), The Digicult Report: Technological Landscapes for Tomorrow's

Cultural Economy. Unlocking the Value of Cultural Heritage, Directorate-General for the Information Society, European Commission, Brussels, available at: ftp://ftp.cordis.europa. eu/pub/ist/docs/digicult/ full_report.pdf (accessed 22 December 2009).

Griffin, S. (2005), "Funding for digital libraries research: past and present", D-Lib Magazine, Vol. 11 Nos 7/8, available at: hwww.dlib.org/dlib/july05/griffin/07griffin.html (accessed 22 December 2009)

Hamilton, V. (2004), "Sustainability for digital libraries”, Librarv Review, Vol. 53 No. 8, pp. 392-5, available at: http://strathprints.strath.ac.uk/2377/1/strathprints002377.pdf (accessed 22 December 2009).

Liew, C.L. (2009), “Digital library research 1997-2007: organisational and people issues”, Lournal of Documentation, Vol. 65 No. 2, pp. 245-66.

Raitt, D. (2000), "Digital library initiatives across Europe", Computers and Libraries, Vol. 20 No. 10, available at: www.infotoday.com/cilmag/nov00/raitt.htm (accessed 22 December 2009).

Smith, A. (2003), "Issues in sustainability: creating value for online users", First Monday, Vol. 8 No. 5, available at: http://131.193.153.231/www/issues/issue8_5/smith/index.html (accessed 22 December 2009).

\section{Further reading}

European Commision (n.d.), CIP ICT-PSP - eContentplus, available at: http://ec.europa.eu/ information_society/activities/econtentplus/index_en.htm

ICT Workprogramme (2009-2010), ICT Workprogramme, available at: http://ec.europa.eu/ information_society/events/cf/document.cfm?doc_id=8939

Idealist: Worldwide ICT Support Network (n.d.), Idealist: Worldwide ICT Support Network, available at: www.ideal-ist.net

TEL (The European Library) (n.d.), TEL (The European Library), available at: http:// theeuropeanlibrary.org

\section{About the authors}

Seth van Hooland holds the chair in Digital Information in the Information and Communication Science department of the Universite Libre de Bruxelles (ULB), Belgium, where he obtained in 2009 his PhD on the topic of metadata quality in the cultural heritage sector. During the current academic year, he is working as a visiting professor in the Library and Information Science 


\section{About the authors}

Seth van Hooland holds the chair in Digital Information in the Information and Communication Science department of the Université Libre de Bruxelles (ULB), Belgium, where he obtained in 2009 his $\mathrm{PhD}$ on the topic of metadata quality in the cultural heritage sector. During the current academic year, he is working as a visiting professor in the Library and Information Science epartment of the Carlos III University of Madrid, Spain. His publications include "Metadata typology and metadata uses" (Handbook of Metadata, Semantics and Ontologies, World Scientific Publishing, London, 2010), "From card catalog to web interface. The evolution of metadata management in the cultural heritage sector" (De Nil, B. and Walterus, J. Erfgoed 2.0. Brussels, FARO, 2009, pp. 87-106). He also works as a Consultant for clients such as the European Commission in the domain of digital cultural heritage. He is a member of the Dublin Core Metadata Initiative (DCMI) Advisory Board and co-chair of the DCMI Tools Community and is involved in the CollectiveAccess project, an open-source collection management software for the cultural heritage sector. Seth van Hooland is the corresponding author and can be contacted at: svhoolan@ulb.ac.be

Franc, oise Vandooren has been working at the libraries Head Office at the Universite' Libre de Bruxelles since 1999. She holds a Master's Degree in Linguistics and has worked as a researcher in computational linguistics in the past. She has participated in various European R\&D projects and she currently deals with digitization activities, digital library management, institutional repository and open access issues. She has been involved in the Open Access Working Group of the European University Association and initiated the Scholarly Communication Group in UNICA (network of universities from the capitals of Europe). She has also served as an independent expert in the evaluation of EU projects for the 7th Framework Programme. She is co-author of the Study on the Economic and Technical Evolution of the Scientific Publication Markets in Europe, published by the European Commission in 2006. Her recent publications include "Evolution de l'acce's aux publications scientifiques" (J. Scho"pfel, La publication scientifique - analyses et perspectives, Hermes Science Publications \& Lavoisier, 2008) and "When publishers' and libraries' interests meet" (with C. Gass, in Learned Publishing, July 2008).

Eva M. Me'ndez Rodri'guez is an Associate Professor at the University Carlos III of Madrid, where she has been teaching and conducting research since March 1997. She holds a PhD in Information Science from the same University, awarded for the outstanding thesis of the year in her field for the academic year 2001-2002. She is a member of the Dublin Core Metadata Initiative (DCMI) Advisory Board and co-chair of the DCMI Social Tagging Community. Her research focuses on Semantic Web technologies applied to digital information systems and services, with an emphasis on metadata standards and vocabularies. She co-edited with Jane Greenberg "Knitting the semantic web" (Haworth Press, 2007). In addition to the DCMI, Eva M. Me'ndez Rodr1' guez has served on many conference and workshop program committees worldwide. She has also served as an advisor on information practice and policy countries in the European Union and Latin America. Eva M. Me'ndez Rodri'guez was Fulbright-EU Research Scholar at University of North Carolina at Chapel Hill, School of Information and Library Science, Metadata Research Center, during the academic year 2005-2006. Currently, she is the Director of the Master's in Digital Libraries, taught in a b-learning educational model at the University Carlos III of Madrid. 